\title{
Application of Magneto-optical Characteristic in Liquid: Verdet Constant as Quality Indicator of Repeatedly Cooking Oil
}

\author{
(Aplikasi Karakteristik Magneto-Optik Pada Zat Cair: Konstanta Verdet Sebagai Indikator \\ Kualitas Minyak Goreng Pada Pemakaian Berulang) \\ Silfiana Puspita Sari, Misto, Endhah Purwandari*) \\ Jurusan Fisika, Fakultas Matematika dan Ilmu Pengetahuan Alam, Universitas Jember \\ Jl. Kalimantan 37, Jember 68121
}

\section{ABSTRACT}

The Faraday Effect is a magnetooptical phenomenon in physics describing the interaction of light and magnetic fields in a medium. A parameter that indicates the interaction is the Verdet constant. In this research, Verdet constant was measured on cooking oil that has been used several times. Magneto-optical properties were measured using the polarimetry method, which uses a He-Ne Laser beam with a magnetic field treatment of 50 gauss, 80 gauss and 100 gauss. The samples analyzed were bulk and non-bulk cooking oil. Repeated use of cooking oil causes a change in the polarization axis of the polarized laser. This has an impact on the Verdet constant of the material. The difference in the Verdet constant shows that the Verdet constant can be used as an indicator of cooking oil that has been used up to three times.

Efek Faraday merupakan sebuah fenomena di dalam fisika yang menggambarkan interaksi cahaya dan medan magnet di dalam medium. Sebuah parameter yang muncul sebagai konsekuensi dari adanya interaksi tersebut adalah konstanta Verdet. Konstanta Verdet diukur pada bahan minyak goreng yang telah dipakai beberapa kali. Pengukuran sifat magneto-optik dilakukan dengan menggunakan metode polarimeter, yang memanfaatkan berkas Laser He-Ne sebagai obyek pengukuran dengan perlakuan medan magnet sebesar 50 gauss, 80 gauss dan 100 gauss. Adapun sampel minyak goreng yang dianalisis adalah minyak goreng curah dan non curah. Pemakaian berulang pada minyak goreng menyebabkan sumbu polarisasi bidang getar dari berkas laser terpolarisasi mengalami perubahan cukup signifikan. Peristiwa ini berdampak pada hasil perhitungan konstanta Verdet dari bahan. Perbedaan cukup signifikan pada konstanta Verdet menunjukkan bahwa konstanta Verdet dapat digunakan sebagai indikator dari minyak goreng yang telah digunakan hingga tiga kali pemakaian.

Keywords: cooking oil, Faraday effect, polarization, Verdet constant.

*)Corresponding author:

Endhah Purwandari

E-mail: endhah.fmipa@unej.ac.id

\section{PENDAHULUAN}

Minyak goreng adalah minyak yang berasal dari pemurnian bagian tumbuhan atau hewan yang biasanya digunakan untuk menggoreng makanan. Konsumsi minyak goreng terbagi dalam dua kategori yaitu minyak goreng kemasan dan curah. Minyak goreng kemasan adalah minyak goreng yang diberi merek dan dikemas dengan botol, plastik refill dan jerigen, dan diukur dalam satuan volume (liter). Minyak goreng curah adalah minyak goreng yang tidak memiliki merek dan diukur dalam satuan massa (kilogram) [1]. Minyak goreng merupakan salah satu jenis bahan transparan yang bersifat optis aktif karena memiliki atom C chiral [2]. Molekul-molekul chiral memiliki kemampuan untuk memutar bidang cahaya terpolarisasi. Parameter kualitas minyak meliputi sifat fisik dan kimia. Sifat fisik antara lain: warna, bau, kelarutan, titik cair dan polimerfisme, titik didih, titik pelunakan, slipping point, shot melting point, berat jenis, viskositas, indeks bias, titik kekeruhan (turbidity point), titik asap, titik nyala dan titip api, sedangkan sifat kimia 
meliputi jumlah asam lemak bebas (free fatty acid/FFA), bilangan peroksida (peroxide value/PV), bilangan asap (smoke point) dan komposisi asam lemak [3].

Efek Faraday merupakan peristiwa yang terjadi apabila seberkas cahaya yang melewati sebuah bahan transparan mendapatkan pengaruh medan magnet eksternal yang kuat. Parameter yang muncul akibat efek Faraday adalah konstanta Verdet [4]. Konstanta Verdet didapat dari perputaran sudut polarisasi cahaya saat dilewatkan pada suatu bahan yang diberi pengaruh medan magnet yang selanjutnya digunakan untuk menghitung konstanta Verdet. Besar sudut polarisasi yang dihasilkan untuk menentukan konstanta Verdet sangat bergantung pada sifat kritis bahan [5].

Penelitian pengukuran konstanta Verdet yang pernah dilakukan sebelumnya mengenai pengukuran konstanta Verdet minyak zaitun untuk sensor medan magnet [6]. Penelitian dilakukan dengan menggunakan lima variasi panjang gelombang, yaitu $405 \mathrm{~nm}, 532 \mathrm{~nm}$, 632,8 nm, $650 \mathrm{~nm}$, dan 804,3 nm. Hasil penelitian untuk nilai konstanta Verdet dengan lima variasi panjang gelombang tersebut adalah nilai konstanta Verdet minyak zaitun tertinggi terjadi pada panjang gelombang $650 \mathrm{~nm}$ dan nilai konstanta Verdet terkecil pada panjang gelombang $532 \mathrm{~nm}$. Oleh karena itu, untuk pengukuran konstanta Verdet minyak zaitun pada penelitian tersebut, panjang gelombang yang baik digunakan pada panjang gelombang $650 \mathrm{~nm}$ dan dapat digunakan sebagai sensor untuk medan magnet dengan perubahan sudut rotasi Faraday.

Berdasarkan uraian di atas, pada penelitian ini dilakukan penentuan konstanta Verdet suatu bahan, dengan mengamati sudut rotasi Faraday yang dihasilkan oleh laser pada saat bahan diberikan perlakuan medan magnet eksternal. Bahan yang akan dianalisis dalam hal ini adalah minyak goreng. Oleh karena temperatur dan sifat bahan dari minyak goreng dapat mempengaruhi besarnya konstanta Verdet, maka perubahan yang dimiliki oleh minyak goreng akibat adanya pemakaian diharapkan turut mempengaruhi konstanta tersebut. Hasil analisis diharapkan dapat memberikan gambaran adanya pengaruh pemakaian minyak goreng terhadap konstanta Verdet. Adapun pemakaian minyak goreng akan dibatasi hanya pada variasi frekuensi pemakaian minyak.

\section{METODE PENELITIAN}

Alat dan Bahan

Alat yang digunakan adalah sumber laser $\mathrm{HeNe}, 2$ buah polarizer, 1 buah solenoida berjumlah 1000 lilitan, wadah kaca transparan yang diisi bahan yang akan diteliti, fotometer, teslameter, dan catu daya DC (Direct Current). Set up alat yang dipakai untuk pengukuran sudut rotasi Faraday ditunjukkan pada Gambar 1.

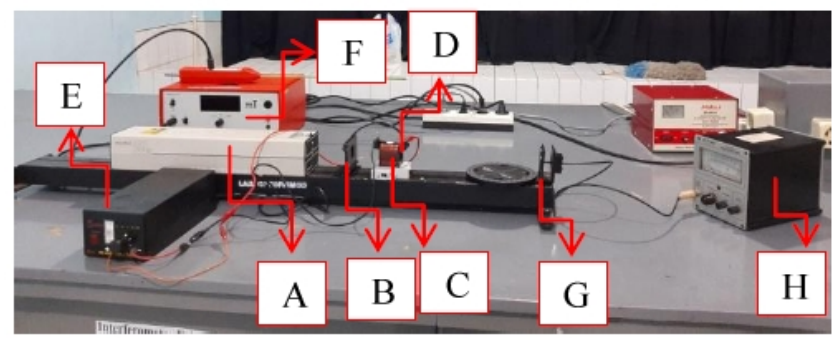

Gambar 1. Set up alat pengukuran sudut rotasi Faraday

Keterangan :

$$
\begin{aligned}
& A=\text { Laser } \\
& B=\text { Polarizer } \\
& C=\text { Solenoida } \\
& D=\text { Sampel } \\
& E=\text { Power supply DC } \\
& F=\text { Teslameter } \\
& G=\text { Analizer } \\
& H=\text { Photometer }
\end{aligned}
$$

Sumber laser HeNe, polarizer 1, solenoid, polarizer 2 (berfungsi sebagai analizer) dan fotometer diletakkan dalam 1 landasan optik sedemikian hingga berkas laser dapat melewati seluruh bagian alat secara lurus. Sampel minyak diletakkan dalam wadah berukuran panjang $3 \mathrm{~cm}$ dan tinggi $1,5 \mathrm{~cm}$, kemudian ditempatkan di dalam solenoida. Pengukuran medan magnet secara seragam dilakukan di bagian tengah solenoid.

Bahan yang digunakan adalah minyak goreng yang terdiri atas kemasan bermerek dan minyak curah. Minyak goreng bermerek yang digunakan ada dua macam (kita sebut merek A dan merek B) dan minyak curah yang diukur juga dua macam (kita sebut curah $\mathrm{C}$ dan D). Minyak goreng bermerek terbedakan atas kejernihan warna yang dimiliki, sedangkan minyak goreng curah diperoleh dari dua toko yang berbeda. Disamping itu, digunakan 
aquadest sebagai bahan kalibrasi penentuan konstanta Verdet.

\section{Penyiapan Minyak Goreng}

Minyak goreng dalam penelitian digunakan dalam berbagai variasi frekuensi pemakaian. Variasi frekuensi pemakaian tersebut adalah minyak goreng sebelum pemakaian (0x), minyak goreng setelah pemakaian pertama (1x), setelah pemakaian kedua (2x), dan setelah pemakaian ketiga (3x). Pada setiap proses penggorengan, tahap pemanasan minyak dilakukan selama 1 menit dengan api konstan, kemudian dilanjutkan dengan proses menggoreng tempe selama 7 menit. Adapun bahan yang digoreng dalam hal ini adalah tempe berukuran sedang. Proses pemakaian minyak goreng dilakukan sama untuk semua sampel minyak goreng yang digunakan yaitu minyak goreng bermerek A dan B, serta minyak goreng curah $\mathrm{C}$ dan D.

\section{Pengambilan Data Sudut Rotasi Faraday}

Pengukuran sudut rotasi Faraday $(\theta)$ dilakukan dengan menembakkan sinar laser $\mathrm{HeNe}(\lambda=632,8 \mathrm{~nm})$ pada polarizer, dimana polizer telah diatur pada keadaan $0^{\circ}$ terhadap analizer yang keadaannya samasama $0^{\circ}$ yang ditunjukkan oleh holder. Laser yang telah ditembakkan diteruskan menuju sampel larutan yang diletakkan di dalam solenoida. Variasi medan magnet yang dihasilkan oleh solenoida secara bergantian adalah sebesar 50 gauss, 80 gauss, dan 100 gauss yang diukur dengan menggunakan teslameter. Berkas laser yang melewati bahan/sampel selanjutnya akan melewati analizer hingga terdeteksi oleh photometer. Seluruh proses pengambilan data dilakukan pada suhu ruang $20^{\circ} \mathrm{C}$.

Pengukuran pertama terhadap intensitas berkas laser dilakukan pada saat laser melewati sampel minyak goreng tanpa diberi medan magnet. Intensitas yang diperoleh merupakan intensitas maksimum dari laser I. Pengukuran dilanjutkan dengan memberikan medan magnet sebesar 50 gauss kepada bahan. Sudut analiser diputar sedemikian hingga dapat menghasilkan nilai intensitas maksimum yang ditunjukkan oleh fotometer (intensitas diupayakan mendekati I). Pemberian medan magnet pada bahan (minyak goreng) akan menyebabkan sudut polarisasi Laser HeNe mengalami perubahan. Hal ini diindikasikan dengan terjadinya penurunan intensitas berkas laser yang terbaca pada photometer. Dengan memutar sudut analiser, akan diperoleh besarnya intensitas maksimum yang ditransmisikan oleh minyak goreng. Posisi sudut yang ditunjukkan oleh analiser dicatat sebagai $\theta 1$. Pengukuran dilanjutkan kembali untuk variasi medan magnet yang lain.

\section{Analisis Konstanta Verdet}

Data sudut rotasi Faraday dan medan magnet yang diperoleh selanjutnya digunakan untuk menentukan konstanta Verdet. Parameter ini dihitung untuk seluruh jenis minyak beserta perlakuan frekuensi pemakaian yang diberikan. Dengan demikian, kita dapat mengetahui hubungan antara konstanta Verdet dengan variasi frekuensi berbagai pemakaian minyak goreng dalam bentuk grafik. Dari grafik tersebut, dapat diketahui karakteristik dan kebergantungan konstanta Verdet terhadap variasi frekuensi pemakaian minyak goreng.

Untuk menentukan konstanta Verdet akibat pengaruh medan magnet digunakan persamaan sebagai berikut:

$$
\mathrm{V}=\frac{\theta}{\mathrm{BL}}(1)
$$

$\theta=$ Sudut rotasi Faraday (perubahan sudut pada analizer dalam radian)

$\mathrm{V}=$ Konstanta Verdet $\left(\right.$ rad.gauss ${ }^{-1}$ cm $^{-1}$ )

$\mathrm{B}=$ Medan magnet (gauss)

$\mathrm{L}=$ Panjang wadah larutan/sampel $(\mathrm{cm})$

Minyak goreng yang diamati dalam berbagai variasi pemakaian untuk data sudut rotasi Faraday diukur sebanyak 5 kali pengulangan. Tingkat presisi terhadap hasil pengukuran dilihat berdasarkan ketidakpastian hasil pengukuran menggunakan standar error (SE).

\section{HASIL DAN PEMBAHASAN}

\section{Sudut Rotasi Faraday Minyak Goreng pada Variasi Frekuensi Pemakaian}

Pada saat laser melewati sampel minyak goreng terjadi perubahan sumbu polarisasi (diukur sebagai sudut rotasi Faraday) dari laser di dalam bahan. Besarnya sudut rotasi yang dihasilkan nilainya dipengaruhi oleh medan magnet eksternal yang dikenakan pada bahan. Nilai sudut rotasi Faraday pada berbagai variasi frekuensi pemakaian untuk 3 variasi medan magnet eksternal ditunjukkan pada Tabel 1.

Berdasarkan tabel tersebut diketahui hubungan antara sudut rotasi Faraday dengan variasi medan 
magnet dan hubungan antara sudut rotasi Faraday dengan variasi frekuensi pemakaian. Nilai sudut rotasi Faraday semakin besar seiring dengan semakin besarnya medan magnet yang diberikan. Hal ini terlihat dari nilai sudut rotasi Faraday berdasarkan medan magnet variasi 50 gauss pada variasi pemakaian sebelum digunakan memiliki nilai rotasi Faraday yang paling kecil untuk semua sampel minyak goreng. Sedangkan pada variasi medan magnet 100 gauss memiliki nilai sudut rotasi Faraday yang paling besar. Hal ini menunjukkan bahwa medan magnet akan mempengaruhi keadaan sudut rotasi Faraday dari gelombang elektromagnetik hingga menyebabkan perubahan sudut rotasi cukup besar pada minyak goreng.

Variasi frekuensi pemakaian minyak goreng memberikan pengaruh terhadap nilai sudut rotasi Faraday yang didapatkan. Semakin sering minyak goreng digunakan untuk menggoreng, maka sudut polarisasinya akan semakin besar. Hal ini terjadi karena proses pemanasan berulang telah mengubah sifat-sifat fisik dari minyak goreng itu sendiri yaitu warna dan kekentalan, sehingga sifat optik dan sudut polarisasi pada minyak goreng mengalami perubahan [3].

\section{Konstanta Verdet Minyak Goreng pada Variasi Frekuensi Pemakaian}

Pengukuran sudut rotasi Faraday diawali dengan melakukan kalibrasi polarimeter menggunakan aquades. Nilai sudut rotasi aquades kemudian digunakan untuk menghitung konstanta Verdet dari aquades yaitu sebesar $23 \times 10^{-5}$ radgauss $^{-1} \mathrm{~cm}^{-1}$. Kemudian nilai konstanta Verdet aquades dibandingkan dengan hasil eksperimen yang dilakukan oleh Sayan (1997), yaitu sebesar 1,3×10 $0^{-5}$ radgauss $^{-1} \mathrm{~cm}^{-1}$ [7] dan menghasilkan faktor koreksi konstanta Verdet sebesar 0,0565. Nilai faktor koreksi ini kemudian diterapkan untuk setiap penentuan konstanta Verdet dari semua sampel minyak goreng yaitu minyak goreng bermerek $A$ dan merek $\mathrm{B}$, dan minyak goreng curah $\mathrm{C}$ dan curah $\mathrm{D}$ pada berbagai variasi frekuensi pemakaian. Profil kenaikan nilai konstanta Verdet dari 4 macam minyak goreng pada berbagai frekuensi pemakaian ditunjukkan pada Gambar 2.

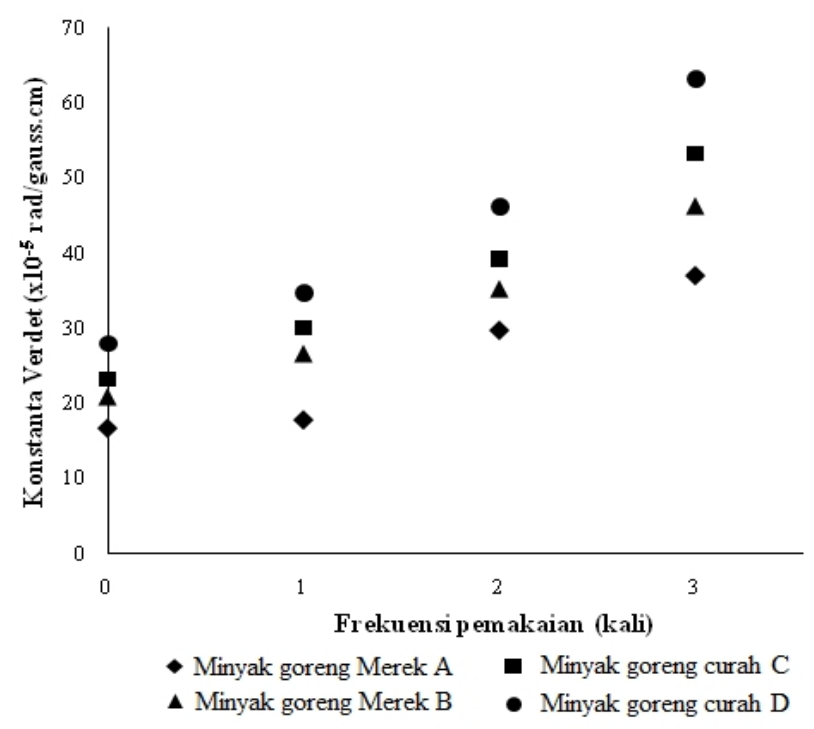

Gambar 2. Grafik hubungan frekuensi pemakaian minyak goreng dengan konstanta Verdet

Secara umum, frekuensi pemakaian hinga 3 kali pakai pada minyak goreng, baik pada jenis minyak bermerek maupun minyak curah menunjukkan trend peningkatan pada nilai konstanta Verdet. Hal ini bersesuaian dengan sudut rotasi Faraday yag meningkat cukup signifikan seiring dengan peningkatan frekuensi pemakaian. Frekuensi pemakaian minyak goreng setelah tiga kali penggunaan dapat memutar sudut rotasi Faraday sangat besar dibandingkan dengan frekuensi pemakaian minyak goreng sebelum digunakan [8].

Kenaikan nilai konstanta Verdet dari dua jenis minyak goreng bermerek dan curah memiliki nilai yang berbeda sehingga membuat grafik meningkat. Nilai konstanta Verdet minyak goreng setelah pemakaian pertama dan pemakaian kedua relatif konstan untuk keempat sampel minyak goreng dimana nilai relatif konstan yang dimaksud adalah selisih nilai untuk minyak goreng pemakaian pertama ke pemakaian kedua untuk setiap sample minyak goreng dengan variasi medan magnet yang berbeda kecil. 
Tabel 1. Sudut rotasi Faraday dari minyak goreng pada berbagai variasi frekuensi pemakaian

\begin{tabular}{ccccc}
\hline \multirow{2}{*}{ Jenis Minyak Goreng } & Frekuensi & \multicolumn{3}{c}{ Sudut Rotasi Faraday (rad) } \\
\cline { 2 - 5 } Pemakaian & 50 gauss & 80 gauss & 100 gauss \\
\cline { 3 - 5 } Merek A & 0 & $0,199 \pm 0,004$ & $0,251 \pm 0,004$ & $0,297 \pm 0,006$ \\
& $1 \mathrm{x}$ & $0,279 \pm 0,006$ & $0,380 \pm 0,009$ & $0,422 \pm 0,003$ \\
& $2 \mathrm{x}$ & $0,307 \pm 0,004$ & $0,422 \pm 0,007$ & $0,513 \pm 0,004$ \\
& $3 \mathrm{x}$ & $0,405 \pm 0,003$ & $0,551 \pm 0,004$ & $0,652 \pm 0,004$ \\
\hline \multirow{3}{*}{ Merek B } & 0 & $0,255 \pm 0,004$ & $0,335 \pm 0,007$ & $0,363 \pm 0,003$ \\
& $1 \mathrm{x}$ & $0,314 \pm 0,006$ & $0,398 \pm 0,007$ & $0,474 \pm 0,007$ \\
& $2 \mathrm{x}$ & $0,391 \pm 0,004$ & $0,513 \pm 0,004$ & $0,631 \pm 0,007$ \\
& $3 \mathrm{x}$ & $0,495 \pm 0,004$ & $0,687 \pm 0,004$ & $0,816 \pm 0,007$ \\
\hline \multirow{3}{*}{ Curah C } & 0 & $0,290 \pm 0,004$ & $0,377 \pm 0,004$ & $0,405 \pm 0,007$ \\
& $1 \mathrm{x}$ & $0,377 \pm 0,004$ & $0,468 \pm 0,007$ & $0,534 \pm 0,004$ \\
& $2 \mathrm{x}$ & $0,502 \pm 0,007$ & $0,551 \pm 0,004$ & $0,722 \pm 0,004$ \\
$3 \mathrm{x}$ & $0,572 \pm 0,003$ & $0,754 \pm 0,007$ & $0,963 \pm 0,007$ \\
\hline \multirow{2}{*}{ Curah D } & 0 & $0,370 \pm 0,007$ & $0,440 \pm 0,007$ & $0,495 \pm 0,007$ \\
& $1 \mathrm{x}$ & $0,485 \pm 0,007$ & $0,548 \pm 0,004$ & $0,618 \pm 0,004$ \\
& $2 \mathrm{x}$ & $0,593 \pm 0,003$ & $0,680 \pm 0,004$ & $0,837 \pm 0,004$ \\
& $3 \mathrm{x}$ & $0,733 \pm 0,004$ & $0,925 \pm 0,004$ & $1,134 \pm 0,007$ \\
\hline
\end{tabular}

Untuk pemakaian ketiga nilai konstanta Verdet minyak goreng bermerek berbeda dengan minyak goreng curah. Pada minyak goreng bermerek A dan merek B, nilai konstanta Verdet memiliki nilai yang relatif konstan dari pemakaian kedua meskipun nilai dari pemakaian kedua ke pemakaian ketiga mempunyai selisih nilai yang cukup besar. Akan tetapi pada minyak goreng curah C dan curah D, nilai konstanta Verdet terjadi kenaikan yang cukup signifikan karena selisih nilai dari pemakaian kedua ke pemakaian ketiga sangat besar. Hal ini terjadi karena minyak goreng bermerek umumnya menggunakan dua kali proses penyaringan. Kadar lemak dan asam oleat yang rendah sehingga membuat minyak goreng bermerek lebih jernih dan lebih banyak mengandung vitamin [1]. Sedangkan untuk minyak goreng curah, umumnya hanya menggunakan satu kali proses penyaringan, kadar lemak dan asam oleat yang lebih tinggi sehingga membuat minyak curah tidak sejernih minyak goreng bermerek dan terkesan lebih keruh warnanya sehingga memiliki respon perubahan medan magnet yang lebih besar yang dapat mempengaruhi nilai konstanta Verdet yang juga besar. Semakin sering minyak goreng digunakan untuk menggoreng, kekentalan minyak goreng mengalami penurunan karena pemanasan yang sering dilakukan. Hal tersebut telah mengubah sifatsifat fisik pada minyak goreng seperti warna, bau dan kekentalan [3]. Dari sini, dapat kita lihat bahwasanya kualitas minyak goreng yang dilihat berasarkan frekuensi pemakaian dapat diidentifikasi berdasarkan konstanta Verdet yang dimiliki oleh bahan.

\section{KESIMPULAN}

Konstanta Verdet minyak goreng dapat dipengaruhi oleh variasi frekuensi pemakaian. Pemakaian minyak goreng hingga sebanyak tiga kali menyebabkan perubahan cukup besar pada sudut rotasi Faraday. Hal ini mengakibatkan konstanta Verdet minyak dari setiap pemakaian mengalami perubahan cukup signifikan. Perbedaan nilai konstanta Verdet dapat menjadi indikator kualitas dari minyak goreng hingga 3 kali pemakaian.

\section{DAFTAR PUSTAKA}

[1] Wijaya, S. 2005. Mengolah Minyak Goreng Bekas. Surabaya: Trubus Agrisana.

[2] Pujiyanto. 2007. Materi Kuliah Kewirausahaan untuk Topik Instrumentasi Optic: Alat Ukur Kadar Gula Alternatif Lain. https://answers.com/topic/electrooptics?cat=techn ology. [Diakses pada: 17 April 2008]. 
Sari et al, Application of Magneto-optical Characteristic ...

[3] Ketaren, S. 1986. Pengantar Teknologi Minyak dan Lemak Pangan. Jakarta: Penerbit Universitas Indonesia.

[4] Sumantri, A. B., S. I. Utomo, dan Setiawan. 2006. "Pengaruh Konsentrasi Larutan Terhadap Nilai Tetapan Verdet dengan Metode Pengukuran Intensitas Cahaya (Rotasi Faraday)". Jurnal Fisika Indonesia: 95-105.

[5] Sugiyarni, A. 2010. Penentuan Konsentrasi Glukosa dalam Gula Pasir Menggunakan Metode Efek Faraday. Surakarta: Universitas Sebelas Maret Surakarta.

[6] Ali, A. S., D. A. Reiam, dan A. A. Anwar. 2000. Verdet Constant Measurement of Olive Oil for Magnetic Field Sensor. Iraq: Ministry of Science an Technology.

[7] Sayyan, K R. 1997. Faraday Effect Rotation for Water and Flint Glass. Physics Department, The College Of Wooster, Wooster, Ohio 44691.

[8] Nailatussaadah. 2009. Pengamatan Perubaban Sudut Polarisasi Cabaya pada Medium Transparan dalam Medan Radio Frequency Sebagai Salab Satu Parameter Kualitas Minyak. Semarang, Fakultas MIPA, Universitas Diponegoro. 